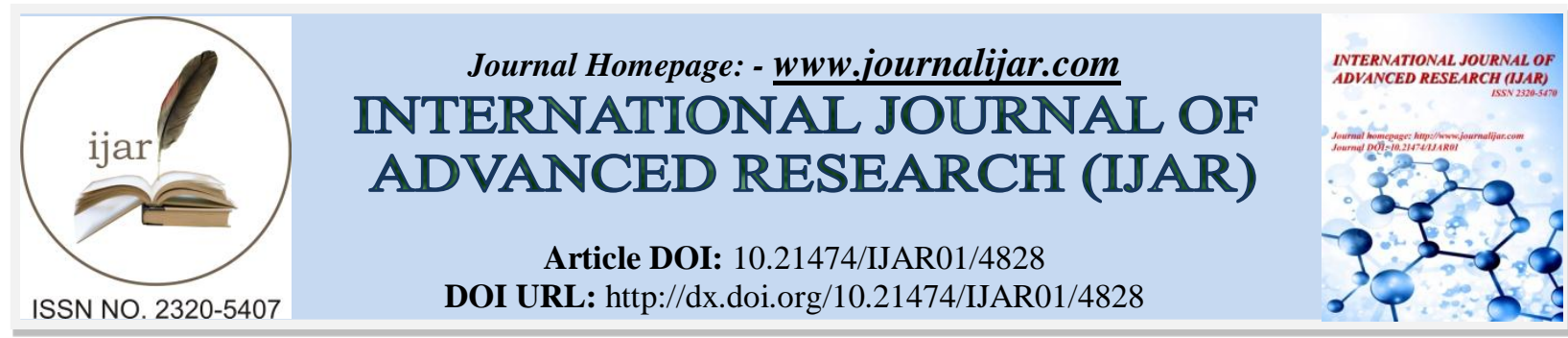

RESEARCH ARTICLE

\title{
IMMEDIATE UROFLOWMETRY AFTER TRANSURETHRAL RESECTION OF PROSTATE: DOES IT HELP IN PREDICTING OUTCOME OF SURGERY.
}

\author{
Dr Mohamad Sajid Bazaz ${ }^{1}$ and Nuzhat Tabasum² \\ 1. Specialist Urology, Al Raffah Hospital, Oman. \\ 2. Medical Officer Health Department Kashmir.
}

\section{Manuscript Info}

.........................

Manuscript History

Received: 12 May 2017

Final Accepted: 14 June 2017

Published: July 2017

Key words:-

Benign prostatic hyperplasia, Uroflowm etry, IPSS scoring

\section{Abstract}

Introduction and Objective: To evaluate the role of immediate uroflowmetry in patients of benign prostatic hyperplasia following transurethral resection of prostate.Methods: 100 patients were included in our study who underwent TURP at our centre. Complete preoperative evaluation was done which included usg prostate, uroflometry and IPSS scoring. Uroflometry was done immediately at the time of catheter removal and after one and three month of surgery. Qmax, IPSS scoring were compared before and after TURP.

Result: The mean patient age in study was 64.52 years. Mean Qmax, AFR and prostate weight were $8.30 \pm 3.26 \mathrm{ml} / \mathrm{sec}, 4.82 \pm 1.72 \mathrm{ml} / \mathrm{sec}$ a nd $46.62 \pm 31.10$ gms respectively. Of the 100 patients, $75 \%$ patients were having immediate $\mathrm{Qmax}>15 \mathrm{ml} / \mathrm{sec}$ and $25 \%$ were having $<15 \mathrm{~m}$ $1 / \mathrm{sec}$. On comparing the mean value of different parameters between $t$ hese two groups it was found that the difference between parameters were not statistically significant. Sensitivity and specificity of immediate uroflowmetry (Immediate Qmax ) were 91.3\% and $61.3 \%$ respectively. Positive predictive value of this test was $84 \%$ and the negative predictive value was $76 \%$. Conclusion: Based on our experience, we conclude that immediate uroflowmetry after TURP can be used as a tool to predict the outcome of TURP up to three months after surgery with good accuracy but can these results be reciprocated on longer follow up need to be evaluated and can immediate uroflowmetry be used as a tool to differentiate those patients which are more likely to get re operated in the future need to be studied. For answering these questions further studies in the same direction with longer follow up period needed to be done.

Copy Right, IJAR, 2017,. All rights reserved.

\section{Introduction:-}

Benign prostatic hyperplasia is the most common disorder of the prostate gland affecting aging men. Histologic hyper plastic growth of prostate begins in approximately $40 \%$ of men aged 50 years and above. By age eighty, almost $90 \%$ of men have histological evidence of benign prostatic hyperplasia (1-3). Patients with BPH have early clinical features like hesitancy, intermittency, frequency, nocturia, urgency, terminal dribbling, polyuria, difficulty in micturation, weak urinary stream, incontinence of urine, and sometimes hematuria (1). Late clinical features will develop more serious sequelae of disease with urinary retention, recurrent urinary tract infection, bladder stone, 
bladder failure, renal dysfunction $(1,4)$. Clinical diagnosis of BPH is made by detailed medical history focusing on the urinary tract, previous surgical procedures and general health issues. For some patients a voiding diary may help in determining the frequency and nature of complaints (5). A thorough physical examination including digital rectal examination and focused neurologic examination should be done in all patients. Quantification of symptom severity is done by the assessment of International prostate symptom score (IPSS). IPSS is recommended as the symptom scoring instrument to be used for the baseline assessment of symptom severity in men presenting with lower urinary tract symptoms. The symptom score is also the primary determinant of treatment response or disease progression in the follow up period.

Several specific diagnostic tests are available to further assess patients with a presumptive diagnosis of BPH. Ultrasound of the prostate is the investigation that enables us to visualize the prostate gland directly and is one of the commonest diagnostic modalities performed nowadays. It gives information about the prostatic volume and post void residual urine (5). Uroflometry is one of the simplest noninvasive urodynamic investigations in the measurement of urinary flow rate using a flowmeter for evaluation of obstructive lower urinary tract symptoms. In spite of certain restrictions, uroflometry yields a high level of information, besides being a simple, at any time reproducible, and non-invasive procedure $(2,6-8)$. It is a common urodynamic test used in the diagnostic evaluation of patients with symptoms of Bladder outlet obstruction. The results of uroflometry are non-specific for causes of symptoms as abnormal flow rates may be caused by an obstruction e.g., hyperplastic prostrate, urethral stricture, meatal stenosis, or by detrusor underactivity. The parameters which are measured during uroflometry are voided volume, flow time and voided time, average flow rate and maximum flow rate and time to maximum flow. The maximum flow rate is the most important single parameter is uroflometry. The reproducibility and reliability of maximum flow rate is best with voided volumes between $200-400 \mathrm{ml}$. A reduced flow rate obtained at volume smaller than 100-150 ml. is unreliable. In male patients, a maximum flow rate exceeding $15 \mathrm{ml} / \mathrm{sec}$ indicates normal bladder and urethral function and maximum flow rate between $10 \mathrm{ml} / \mathrm{sec}$ to $15 \mathrm{ml} / \mathrm{sec}$ are suggestive of infravesicle obstruction.

Transurethral resection of prostrate is the most widely accepted surgical method of treating prostatic urethral obstruction in patients with BPH and is considered the gold standard against which other treatments should be compared $(9,10)$. Comparison of the results of uroflometry performed in patients with large or small adenomas showed that TURP was successful in both groups.

\section{AIM of the study:-}

The aim of this study is to evaluate the role of serial uroflowmetry tests in patients of benign prostatic hyperplasia following transurethral resection of prostate

\section{Material and Methods:-}

Study Design: Hospital based prospective study

\section{Inclusion Criteria:-}

All men who underwent transurethral resection of prostate for bladder outlet obstruction due to benign prostatic hyp erplasia were recruited in the study.

Sample size: 100 cases

\section{Exclusion Criteria:-}

\section{Following patients will be excluded from the study:}

- CA Prostrate.

- Urethral stricture.

- Neurological diseases

\section{Methodology:-}

A careful medical history was taken and a thorough physical examination including digital rectal examination was $\mathrm{d}$ one. IPSS was assigned to all patients as per the

IPSS questionnaire. Patients had undergo investigations including ultrasound KUB with postvoid residual urine, uri ne routine and microscopy, urine culture and sensitivity, serum prostate specific antigen level, renal function test and 
blood sugar levels. Uroflowmetry was done in all patients as a baseline pre-operative record of the level of obstructi on. Impact on quality of life was assessed by IPSS associated QOL index because of urinary symptoms.

Catheter was removed on $5^{\text {th }}$ postoperative day. Uroflometry was done immediately after the removal of the catheter . This gave an early assessment of the flow of urine after TURP. Maximum flow rate (Qmax) was taken as the varia ble on which good flow was differentiated from the poor flow. Patients with Qmax $>15 \mathrm{ml} / \mathrm{sec}$ was taken as having good flow while those with $<15 \mathrm{ml} / \mathrm{sec}$ as having poor flow. On the basis of this differentiation patients with Qmax on immediate uroflowmetry patients were divided into two groups; group I- those with Qmax > $15 \mathrm{ml} / \mathrm{sec}$ and group II - those with Qmax $<15 \mathrm{ml} / \mathrm{sec}$.

Patients from both groups were advised to come after 1 month and 3 months for follow-up visits. In each visit, the $\mathrm{p}$ atients were evaluated through history and physical examination. IPSS and quality of life assessment was done as pe $r$ the IPSS questionnaire. Uroflowmetry was done during each visit. The results were co-related in terms of the impr ovement in the IPSS, QOL and Qmax after TURP and whether uroflowmetry done immediately after catheter remov al can predict the outcome of the surgery and can it differentiate those patients who are more likely to have problem in the future.

\section{Results:-}

The mean patient age in study was 64.52 years (standard deviation 9.11, range 42-92 years) Mean IPSS was $22.25 \pm$ 4.64 and mean QOL score was $4.38 \pm 0.693$.Uroflowmetry and USG KUB was done in all patients. Mean Qmax, AF $\mathrm{R}$ and prostate weight was $8.30 \pm 3.26 \mathrm{ml} / \mathrm{sec}, 4.82 \pm 1.72 \mathrm{ml} / \mathrm{sec}$ and $46.62 \pm 31.10$ gms respectively. : Out of $100 \mathrm{p}$ atients, 96\% had Qmax less than $15 \mathrm{ml} / \mathrm{sec}$ while the remaining $4 \%$ had more than or equal to $15 \mathrm{ml} / \mathrm{sec}$. Of the $100 \mathrm{p}$ atients, 66\% had IPSS in the range of 20-35(severe), 34\% in 8-19 range (moderate) while none in 0-7 range (mild). Post TURP, patients were evaluated after 1 and 3 months with IPSS, QOL and uroflowmetry. At one month of follo w up, the mean Qmax was 18.44 \pm 4.80 and the mean IPSS and QOL score was $4.67 \pm 2.49$ and $1.91 \pm 1.08$ respecti vely. At three month follow up the mean of Qmax, IPSS and QOL score was 16.61 $\pm 4.03,6.47 \pm 3.80$ and $1.79 \pm 1$. 03 respectively. There was statistically significant difference between preoperative and postoperative Qmax, Av flo w, IPSS and QOL with p value less than 0.001 for all parameters. In all patients uroflowmetry was done immediatel y after catheter removal and patients with Qmax $>15 \mathrm{ml} / \mathrm{sec}$ were considered as having good flow whereas patients with Qmax $<15 \mathrm{mi} / \mathrm{sec}$ were considered as having poor flow. On the basis of this distribution, patients were distribut ed into two groups those with immediate Qmax $>15 \mathrm{ml} / \mathrm{sec}$ and those with $<15 \mathrm{ml} / \mathrm{sec}$. Of the 100 patients, $75 \%$ pati ents were having immediate $\mathrm{Q} \max >15 \mathrm{ml} / \mathrm{sec}$ and $25 \%$ were having $<15 \mathrm{ml} / \mathrm{sec}$. On comparing the mean value of di fferent parameters between these two groups it was found that the difference between parameters was not statisticall y significant. Sensitivity and specificity of immediate uroflowmetry (Immediate Qmax were 91.3\% and 61.3\% resp ectively. Positive predictive value of this test was $84 \%$ and the negative predictive value was $76 \%$

\section{Discussion:-}

BPH has significant impact on quality of life. Urinary symptoms are usually related to a subjective decrease in qualit y of life. Uroflowmetry is generally recommended in all patients for evaluation and before invasive treatment. As pe $\mathrm{r}$ the AHCPR Guideline Panel flow rate recording is the single best noninvasive urodynamic test to detect lower urin ary tract obstruction and the peak flow rate (PFR; Qmax) more specifically identifies patients with BPH than does th e average flow rate (Qave). The Fourth International Consultation on BPH concluded that flow rate measurement re presents a reproducible way to quantify the strength of the urinary stream and, when used in combination with sympt om scores has a high probability of correctly characterizing whether there is BOO (Denis et al, 1998). PFR appears $t$ o predict surgical outcome in some studies. In one study reported by Jensen and coworkers (1984), 53 patients under went prostatectomy based on clinical indication alone. All three groups according to level of PFR experienced impro vements in their symptom score after surgery, but the group with a PFR less than $10 \mathrm{ml} / \mathrm{sec}$ before treatment had a b etter overall subjective outcome as assessed by global subjective judgment. In another study, which included men st udied with flow rates before and 6 months after prostatectomy (Jensen et al, 1988a), subjective evaluation revealed a n overall symptomatic improvement rate of $80 \%$ after surgery. The difference in success rates for men falling above or below the cutoff value of PFR $=10 \mathrm{~mL} / \mathrm{sec}$ was not significant $(P=.2)$. When a PFR cutoff of $15 \mathrm{ml} / \mathrm{sec}$ was use $\mathrm{d}$, success rates for men above or below the cutoff value differed significantly. In our study, uroflowmetry was done in all patients and Qmax was used as a representative of uroflowmetry as it specifically identifies patients with obstr uction. The cut off value of $15 \mathrm{ml} / \mathrm{sec}$ was taken. Patients with Qmax above $15 \mathrm{ml} / \mathrm{sec}$ were considered as having goo d flow whereas those with Qmax less than $15 \mathrm{ml} / \mathrm{sec}$ as having poor flow. Out of 100 patients in our study, $96 \%$ had 
Qmax below $15 \mathrm{ml} / \mathrm{sec}$ while $4 \%$ had above this value. In our study, a strong negative correlation was found between Qmax and IPSS while a weak correlation was present between Qmax and QOL. Strong positive correlation was foun $\mathrm{d}$ between IPSS and QOL. In one study while comparing Qmax with total IPSS score, Bright E observed a significa $\mathrm{nt}$ negative correlation between them in 100 patients attending uroflowmetry clinic. $\left((\mathrm{r}=-0.295, \mathrm{P}=0.003)^{42}\right.$. The res ults were consistent with the results obtained in our study as suggested by significant correlation between IPSS score and Qmax (r=-0.440, p.002).

In our study, the mean preoperative Qmax was $8.30 \pm 3.26$ that changed to $18.44 \pm 4.80$ and $16.61 \pm 4.03$ at one and three month after TURP respectively ( $\mathrm{p}$ value $<0.001$ ).In a prospective study by Daimantas Milonas the Qmax chan ged from $8.67+2.77$ preoperatively to $18.75+7.79$ after six months of TURP.

In our study, we found that the mean QOL score preoperatively was $4.38 \pm 0.693$ which improved to $1.79 \pm 1.03$ aft er TURP and the change was statistically significant ( $\mathrm{p}$ value $<0.001$ ). Similar results are reported by Chalise PR et al who studied 50 patients and found that the preoperative QOL score was $5.2+0.6$ that changed to1.5+0.7. In our st udy, the effect of TURP on different parameters was assessed and it was found that the change in IPSS, Qmax and Q Ol score in our study was 15.55, 8.3 and 2.59 respectively. Similar results were observed by Daimantas Milonas in 8 9 patients who underwent TURP at their centre. The changes in different parameters after TURP in his study were 1 $6.8,10.08$ and 3.6 respectively. In our study, we did uroflowmetry in all patients immediately after catheter removal (post-TURP). The aim of this uroflowmetry was to assess whether it can predict the outcome of the surgery in the fu ture and whether it can differentiate those patients who are more likely to develop voiding difficulties in future. Afte $\mathrm{r}$ thoroughly searching the literature we could not find any study in which uroflowmetry was done immediately after catheter removal in TURP patients.

Out of the 100 patients in our study, 75\% had immediate Qmax > $15 \mathrm{sec}$ (Good flow) while $25 \%$ had $<15 \mathrm{ml} / \mathrm{sec}$ (p oor flow). All patients were followed at one and three month with uroflowmetry. Of the 75 patients in Group I, good flow after one and 3 month of surgery was seen in $94.7 \%$ and $84 \%$ respectively. Out of 25 patients in Group II, poor flow was seen in $72 \%$ and $76 \%$ at one and three month after surgery respectively. The difference between mean of $p$ reoperative parameters in two groups was assessed. No statistically significant difference was seen for any paramete $r$ indicating that preoperative parameters had no effect on immediate uroflowmetry. At 3 months of follow up, there was statistically significant difference between mean of Qmax, IPSS and QOL between the two groups. The mean Q max at three month in group I was $18.04+3.29$ compared to $12.31+2.84$ in group II, while the mean IPSS in group I was $5.47+3.19$ compared to $9.48+3.95$ in group II. The QOL score in group I at three month was $1.55+0.920$ while in group II it was $2.52+1.005$. These statistics revealed that patients with immediate good flow (group I) faired signi ficantly better at 3 months after TURP than those with immediate poor flow (group II) indicating that immediate uro flowmetry can predict the outcome of the surgery in the future and can help us counsel patients who are more likely to develop urinary problems in the future. The positive predictive value of this test in our study was $84 \%$ and the neg ative predictive value was $76 \%$ with sensitivity and specificity of $91.3 \%$ and $61.3 \%$ respectively. This further establi shes the fact that immediate Uroflowmetry can be used as a tool to predict the outcome of surgery in the future with fairly good accuracy. Whether similar results will be reciprocated on longer follow up need to be seen.

In our study, no patient in the either group required operative intervention again within 3 months of TURP but on lo nger follow up of some patients, four patients from group II required reoperation while none from the group I requir ed reoperation. Whether immediate uroflowmetry can predict the rate of reoperation after TURP cannot be answered from our study probably because of shorter follow up. Further studies with longer follow up period are needed to ans wer these questions.

\section{Conculsion:-}

Based on our experience, we conclude that immediate uroflowmetry after TURP can be used as a tool to predict the outcome of TURP up to three months after surgery with good accuracy but can these results be reciprocated on long er follow up need to be evaluated and can immediate uroflowmetry be used as a tool to differentiate those patients which are more likely to get re operated in the future need to be studied. For answering these questions further studie $\mathrm{s}$ in the same direction with longer follow up period needed to be done. 


\section{References:-}

1. Malik H.J, Kumar A., Dinari .R.A., Soomro I,. Effects of transurethral resection of prostate on uroflometry parameters on patients having benign prostatic hyperplasia. Medical Channel, Journal of modern Medical and Dental Sciences July- Sep 2009; 32: 45-54.

2. Mc Kkelive GB, Collins GN, Hehir M, Rogers CN. A study of benign prostatic hyperplasia- a challenge to British urology. Br J Urol 1993; 71: 38-42.

3. Grino PB, Bruskewtiz R, Blaivas JG, etal: maximum urinary flow rate by uroflowmetry: Automatic or visual interpretation. J Urol 1993; 149(3): 339-341.

4. Peter P.C, Boone T.B, Frank I.N, MC Conell J.D and Preminger G.M. Schwartz- Principles of surgery 6th Ede, 1998(9) 1753-55

5. Malik M.A., Khan J.H., Gondal W.S., Bajwa I.A. Role of Uroflowmetry in Lower Urinary Tract Symptoms Evaluation due to Benign Prostatic Hyperplasia (BPH). Special edition annals Jan - Mar 2010 ; vol 16 : 67-82.

6. Karl.C, Gerlach. R; Hannappel. J, Lehnen.H. Investigation of pre- and postoperative measurements. Urol, Ink. 1986; 41 (4): 270-75.

7. Jensen K.M, Jorgensen J.B, Mogensen P. Reproducibility of uroflowmetry variables in elderly males'.Urol Res 1985: 13: $237-239$.

8. Drach G.W, Steinbronn D.V. Clinical evaluation of patients with prostatic obstruction: correlation of flow rates with voided, residual or total bladder volume. J Urol., 1986 135(4):737-40

9. Blaivas J.G, Chancellor M.B. Transurethral incision of the prostate: An alternative to prostatectomy. Prob In Urol 1991: 5 (3): 412-417.

10. Tanaka Y, Masumori N, Tsukamoto T, Furuya S, Furuya R, Ogura H. Longterm results of lower urinary tract symptoms and urinary flow rate after transurethral resection of the prostate. Hinyokika Kiyo., 2007; 53 (6):36973.

11. A.J. Harding Rains, Charles V, Manna Baily and love's, short practice of surgery 20th Ede: 1299-1308. 